\title{
Adolescent Proactive Bystanding Versus Passive Bystanding Responses to School Bullying: the Role of Peer and Moral Predictors
}

\author{
Marilyn Campbell ${ }^{1}$ (D) $\cdot$ Kirstine Hand ${ }^{1} \cdot$ Therese Shaw $^{2} \cdot$ Kevin Runions $^{2} \cdot$ Sharyn Burns ${ }^{3} \cdot$ Leanne Lester $^{3}$. \\ Donna Cross ${ }^{2,4,5}$
}

(C) Springer Nature Switzerland AG 2020

\begin{abstract}
Bystanders to bullying perpetration are considered an extremely important group to engage in bullying prevention and intervention. It is important to understand the key differences between students who are proactive bystanders, who try to stop the bullying and those bystanders who observe but take no action to help the student being bullied. Of 1,231 secondary students (aged 11 to 15 years) surveyed in 12 Australian schools, only 26.9\% (509) reported they had not witnessed any bullying. The actions taken by student witnesses were grouped into proactive bystanding $(786,41.5 \%)$ and passive bystanding $(445,23.5 \%)$ responses. Age, gender, victimisation, being connected to school, perceived peer support and moral engagement were examined. The strongest predictor for proactive bystander responses was previous experience of bullying victimisation. Feeling connected to school, having higher levels of peer support and being morally engaged also predicted proactive bystander behaviour. Age and gender were not associated with being a proactive bystander or a passive bystander. Implications for school policy and practices to prevent and reduce peer bullying behaviour are discussed.
\end{abstract}

Keywords Bullying $\cdot$ Schools $\cdot$ Passive bystanders $\cdot$ Proactive bystanders $\cdot$ Witness $\cdot$ Moral disengagement

Bullying among children and young people is not only a worldwide public health problem, it is also one of the most entrenched antisocial behaviours in society. Whether this is because the behaviour is a consequence of evolution or social learning or both (Campbell 2017), reducing bullying perpetration is extremely difficult to accomplish despite many programs and other efforts to do so (Ttofi and Farrington 2011). Bullying has been conceptualised away from the dyadic view of a bullying perpetrator and a young person who is victimised, to include all participant roles including those who witness bullying, the bystanders (Espelage and Swearer 2004).

Marilyn Campbell

ma.campbell@qut.edu.au

1 School of Early Childhood and Inclusive Education Faculty of Education, Queensland University of Technology, A Block, Victoria Park Road, Kelvin Grove, Queensland 4059, Australia

2 Telethon Kids University of Western Australia, Nedlands, Australia

3 Curtin University of Western Australia, Perth, Australia

4 The University of Western Australia, Perth, Australia

5 Edith Cowan University, Perth, Australia
Bystanders may be directly supportive of the bullying while others may help or defend the bully or ignore the bullying. In their seminal study, Salmivalli et al. (1996) identified four types of bystanders: assistants, reinforcers, defenders (i.e. supporters of the victim) and outsiders. Assistants may not initiate bullying but actively join in once it is established. Reinforcers provide approval through observation and/or laughing. Outsiders act as truly passive bystanders and avoid the bullying situation. Other bystanders may act in the way that can be described as 'defenders' or 'supporters': proactive bystanders where a student takes proactive measures to help or support the target of the bullying. The literature suggests assistants and reinforcers support bullying behaviours while defender and outsiders are negatively associated with the behaviour (Yun 2019).

However, little is known about why some students take proactive bystanding roles supporting the target of bullying, and why others take more passive bystanding roles. This is especially the case for secondary school students, for whom most bullying prevention programs have been shown to be ineffective or even counterproductive (Yeager et al. 2015). Thus, this study examined factors based on the risk and protective factor theory, which postulates that problem behaviours are embedded in a common, overlapping group of risk 
and protective behaviours (Coie et al. 1993; Rolf et al. 1990). These include the demographics of age and gender; the social context of the bystanders, that is, being previously victimised, being connected to school and their perceived peer support as well as the moral engagement of the bystander to understand why some adolescents take a proactive versus a passive role when they witness bullying.

\section{Demographic Predictors of Bystander Behaviour}

Age and gender have been found to be predictors of acting proactively as a proactive bystander. Younger students (grades 4-6) have been shown to be more likely than older students (grades 7-12) to show defending responses (Padgett and Notar 2013; Trach et al. 2010). However, other studies have shown that older adolescents were more likely to intervene to assist the target than younger adolescents (Barhight et al. 2013; Chapin and Brayack 2016). The recent metaanalysis of defending responses to peer victimisation by Ma et al. (2019) found, based on 52 studies involving 41,919 participants, a higher proportion of young children exhibited proactive bystander behaviours than older children.

Girls have been shown in some research to be more proactive in defending than boys (Menolascino and Jenkins 2018; Meter and Card 2015; Salmivalli 2010) while other studies have found no gender differences in bystanders' defending behaviours (Chapin and Brayack 2016). A recent study of early adolescents (Grades 6-8) found girls to be more likely to offer comfort and support while boys were more likely to be aggressive defenders (Lambe and Craig 2020). Therefore, it is still not clear what impact age and gender has on defending behaviour in bullying situations.

\section{The Social Context of Bystander Responses}

Young people who had been victimised themselves were found in one study to be less likely to intervene on behalf of other victims because of their fear of retaliation (Baldry 2005). However, many other studies have showed that victimized students were more likely to help other students being victimised (Batanova and Loukas 2014; Huitsing et al. 2014; Rigby and Johnson 2006). Thus, it is unclear if being victimised prior to witnessing bullying is a predictor of proactive bystander or passive bystander responses.

Being connected or feeling a strong sense of belonging to school has many benefits for students including an association with high grades (Pate et al. 2017), less depression (Wilson et al. 2018) and less risky use of substances (Han et al. 2015; Weatherson et al. 2018). Students who feel they matter to their peers and teachers are more tolerant of difference and respectful to others (Ahmed 2008). These findings suggest that students with a greater sense of belonging are more likely be proactive bystanders, as indeed was found by one study (Ahmed 2008).

Perceived peer support plays a critical role in prosocial and aggressive behaviour (Dishion et al. 2012), especially as friends become increasingly important when adolescents are making decisions (Volk et al. 2016). Rigby and Johnson (2016) found that students who believed that friends expected them to support students who were victimised were more willing to intervene, and high levels of peer pressure were positively associated with bystanders' defending behaviour among middle school students (Sandstrom et al. 2012). It is unclear whether this willingness to intervene is limited to one's own friends, or whether students with high social status, who are well integrated into their peer network, and feel well supported by peers, are also more likely to intervene.

\section{Moral Disengagement in Bystander Response}

Almost all adolescents are aware that bullying is morally transgressive (i.e. wrong; Bussey et al. 2015), and yet bullying continues through adolescence. In his social-cognitive theory, Bandura (2002) proposed a set of integrated cognitive processes that serve to enable individuals to disengage from their own moral values and commitments to allow them to act to harm others, and/or to reduce moral self-censure when acting in ways they know to be wrong. These five mechanisms of moral disengagement include diffusion of responsibilitywhen there are others who are also failing to behave in line with moral expectations, one can more readily recuse oneself from those expectations; distortion of consequences., that is bullying might 'build' and victim blame - attributing reasons why the moral code can be violated due to faults of the target is another mechanism. Moral justification, the espousal of putative bigger, and more important moral factors that require the violation of moral rules such as in the sense of the maxim that the ends justify the means and euphemistic labelling are also mechanisms of moral disengagement which could influence bystander behaviour.

Conceptually, some mechanisms of MD seem more likely to be involved in the decision not to help a fellow student who is being bullied. The one study which reported on specific mechanisms found diffusion of responsibility and victim blame were significant in predicting defending; the other mechanisms were not significant. Further study on the role of specific mechanisms of moral disengagement in defending is essential to development of targeted anti-bullying interventions and to replicate the work of Thornberg and Jungert (2014).

The role of moral disengagement in helping a target may also differ for boys and girls. In a study of senior high school 
students, Thornberg and Jungert (2013) found high moral disengagement in boys was associated with low levels of defending, but there was no significant association of moral disengagement and defending for girls. Neither study, however, examined gender moderation of specific mechanisms, such as moral diffusion of responsibility, distortion of consequences and victim blame, which could help to clarify gendered patterns of moral disengagement and decision making about defending against bullying.

The current study thus sought to identify the factors associated with proactive bystander and passive bystander responses among witnesses to bullying, and hence potential targets for prevention and intervention programs. The study explored age, gender, victimisation experiences, connectedness to school, perceived peer support and moral disengagement as independent predictors of proactive and passive bystanding among secondary school students. In our study, proactive and passive bystanders were considered to be those students who have not encouraged the bullying behaviours. Bystanders who encouraged or actively reinforced bullying were excluded from our analysis. In addition, this study aimed to determine the role of specific mechanisms of moral disengagement and whether gender moderated the association between those specific mechanisms and bystander response, which has not been examined previously.

\section{Method}

\section{Participants and Procedure}

This study is based on data collected as part of a larger grouprandomised intervention trial of the Friendly Schools antibullying intervention. The data reported in this study were collected at baseline from Grade 7 to 9 students (typically 12-14 years of age) attending 12 schools in Australia in 2015. Of the 1231 students, $51.2 \%(n=630)$ were female, ages ranged from 11 to 15 years (mean age of 13 years; S.D. $=0.91)$. There were $2.4 \%$ of students who identified as Indigenous (either Aboriginal or Torres-Strait Islander) and 14.4\% indicated a language other than English was spoken at home. Most students were recruited through the opt-out parent consent process and, hence, from non-government schools $(n=999,81.2 \%)$.

Prior to recruitment, approval was obtained from the Human Research Ethics Office of the University and the offices of the State Department of Education (government schools) and Catholic Education (non-government schools). Government schools required active parental (opt-in) consent; non-government schools permitted opt-out consent for student survey completion. In all cases, schools contacted parents on three occasions (two emails and a letter sent home) with a web link to a consent portal, in addition, an item describing the study was included in the school newsletter. No inducements to encourage the return of parental consent forms (e.g. entry in a draw for returning forms) were permitted in government schools. For opt-in schools, of an estimated 4785 eligible students, parental consent was received for 339 participants (7\%). By contrast, for the opt-out schools, consent was obtained for $1597(80 \%)$ of an estimated 1996 students. This resulted in a combined $28.6 \%$ consent rate. Data were only collected from students for whom we had active parental consent (opt-in) in government schools and passive parental consent (opt-out) in non-government schools.

Surveys were completed within normal class periods and were supervised by school staff who were provided detailed survey administration protocol emphasising the voluntary nature of student participation and the need for teachers to maintain the confidentiality of student responses. A total of 1895 students completed the online survey. For the current study, a subsample of 1231 students was selected based on responses to bystander behaviour question/s to enable the examination of factors predictive of proactive bystander responses to observed bullying (see details in 'Measures' section).

\section{Measures}

\section{Bystander Behaviour}

We developed and included the following question in our survey: 'What did you do the last time you saw bullying between students in your grade level?' with respondents able to identify as many of the seven possible responses as was appropriate. Many of the items were adapted from those used in the Student Bystander Behavior Scale (Thornberg and Jungert 2013), although this latter scale measures likely or usual behaviour to witnessing peer bullying (i.e. 'If you saw bullying...', 'how did you use to react...?'). We worded our question to measure the young person's response to the most recent witnessed incident, to allow for multiple responses to the incident as well as to assess the nature of the response, e.g. did 'nothing, but I thought I ought to help' and did 'nothing, because it was fun to watch'. There was a total of seven responses: 'Nothing, not my business', 'Nothing, but I thought I ought to help', 'Nothing, because it was fun to watch', 'I joined in the bullying', 'I tried to get the bully/bullies to stop', 'I told a teacher or other adult at school' and 'I have never seen any student bully another student at school'.

The two responses 'Nothing, it's none of my business' and/ or 'Nothing, but I thought I ought to help' were coded as a passive bystanding reaction and the two responses 'I tried to get the bully/bullies to stop' and/or 'I told a teacher or other adult at school' as proactive bystander responses. Students who had 'never seen any student bully another student at school' ( $n=509,26.9 \%)$ were excluded, as were the twenty students $(1.1 \%)$ who gave exclusively negative responses 
saying they did 'Nothing, because it was fun to watch' and/or 'joined in the bullying'. Also excluded were the students who indicated a complex combination of proactive bystander, and negative responses to the survey questions $(n=97,5.1 \%$; missing $n=38,2 \%$ ).

\section{Bullying Victimisation}

The frequency of different forms of bullying victimisation was measured using the Forms of Bullying Scale-Victimisation (FBS-V). The FBS-V comprises 10 items to measure verbal, physical and relational forms of bullying. The validity and reliability of responses to the scale has been demonstrated (Shaw et al. 2013). Example items are 'I was teased in nasty ways' and 'Secrets were told about me to others to hurt me' and responses given on a 5-point scale 'This did not happen to me' (1); 'Once or twice' (2); 'Every few weeks' (3); 'About once a week' (4); 'Several times a week or more' (5). Responses were aggregated into a mean score (range 1-5). Cronbach's alpha for responses to the FBS-V in the current study was $\alpha=0.90$.

\section{School Connectedness}

The Add Health School Connectedness Scale (Furlong et al. 2011) was used to measure feelings of connection with school. The five- item scale uses a 5-point Likert scale from 'Strongly Disagree' (1) to 'Strongly Agree' (5). Example items included 'I feel close to people at this school' and 'I feel safe in my school'. A mean score of the items was calculated. Cronbach's alpha in this study was $\alpha=0.87$.

\section{Peer Support}

Self-reported support from peers at school was assessed using a 6-item scale adapted from the 24-item Perceptions of Peer Social Support Scale (Ladd et al. 1996). Respondents were asked how often students in their grade level provided different forms of support such as explaining something or helping when hurt. Students rated the frequency of support on a 3point scale ranging from 'Lots of times (1)' to 'Never (3)' and a mean of the items was calculated. Cronbach's alpha based on these data was $\alpha=0.88$ and a one-factor model was partially supported $(n=1818$; RMSEA $=0.091,95 \%$ CI 0.078-0.104; CFI = 0.986).

\section{Moral Disengagement}

The Moral Disengagement in Bullying Scale (MDBS) is an 18-item self-report scale which assesses the extent to which young people endorse distinct mechanisms of MD with regard to peer victimisation (Thornberg and Jungert 2014). The MDBS is comprised of several subscales. To reduce respondent burden, based on the findings of Thornberg and Jungert (2014), five subscales were chosen for inclusion in the survey, resulting in a 14-item version of the MDBS. These included scales for moral justification, euphemistic labelling, victim blame, diffusion of responsibility and distortion of consequences. Items were scored on a five-point Likert scale ranging from 'Strongly disagree' (1) to 'Strongly agree' (5). Examples of questions include 'It's okay to hurt a person a couple of times a week if you do that in order to help your friends' (moral justification); 'Teasing a person a couple times a week is no big deal because you don't really hurt the person' (euphemistic labelling) and 'If people are weird, it is their own fault if they get bullied' (victim blame).

Confirmatory factor analysis (CFA) in MPlus was used to test the factor structure implied above. All data were treated as multinomial categorical, using the weighted least squared means and variance (WLSMV) estimator. CFA results indicated the 5-factor model provided good fit for the data $(\mathrm{CFI}=$ 0.97; TLI $=0.99$; RMSEA $=0.074$ ). Cronbach's alpha for responses to the full scale in the current study was $\alpha=0.91$ (Kline 2005).

\section{Data Analyses}

IBM SPSS Statistics 23.0 was used for descriptive and regression analyses. Chi-square and $t$ tests were used to determine differences in predictor variables by proactive and passive bystander groups. Binary logistic regression analysis was applied to identify factors associated with proactive bystander responses in trying to stop other students from being bullied (tried to stop it or told a teacher or adult) as opposed to students being passive bystanders. A manual backward variable selection process was utilised to determine the most parsimonious model, i.e. all the factors under investigation were included in the first model and non-significant variables deleted one-by-one in subsequent models. All models included the variables gender, age, an indicator for the parental consent process (opt-in/opt-out), victimisation, connectedness and peer support. The possible moderation effect of gender on the association between moral disengagement and bystander response was tested by the inclusion in the final models of an interaction between gender and the moral disengagement score for the total scale and subscales.

The final models were refitted as a generalised mixed model with logistic link accounting for the clustering of students within schools. As the results were substantively the same as those from the model not including a random effect for school and the variance component did not differ significantly from zero $(p=.656)$, the results from the logistic regression assuming independent errors are presented. Missing data of independent variables was minimal, ranging from 3 to $4.5 \%$. Cases with missing data were not included in the final regression analyses. 


\section{Results}

Close to two-thirds of the subsample of 1231 students were included in the proactive bystander response group $(n=786$, $63.9 \%$ ), with the remainder in the passive bystander group $(n=445,36.1 \%)$. Univariate tests for the two bystander groups are given in Table 1. Based on the univariable tests, the demographic groups did not differ significantly with regard to their response as a bystander, except that students in the proactive bystander group tended to be younger on average (13.03 years) than those in the passive bystander group (13.17 years). Furthermore, the proactive bystander group also scored significantly higher on bullying victimisation, peer support and school connectedness, but were less morally disengaged.

The correlation matrix of study variables (Table 2) shows bystander behaviour was significantly correlated with age, victimisation, peer support, school connectedness and moral disengagement. The age and gender demographic variables were also significantly correlated with victimisation, peer support, school connectedness and moral disengagement.

Separate binary logistic regression models were used to determine the association between moral disengagement subscales (moral justification, euphemistic labelling, diffusion of responsibility, distortion of consequences, victim blame), total moral disengagement and odds of proactive bystander versus passive bystander response. All models adjusted for demographic variables, bullying victimisation, school connectedness and peer support. Results for the final binary logistic regression models are shown in Table 3. The strongest predictors of proactive bystander response were having a history of being bullied (OR $=1.89,95 \%$ CI 1.51, 2.38), peer support $(\mathrm{OR}=1.54,95 \%$ CI $1.17-2.03)$ and school connectedness $(\mathrm{OR}=1.25,95 \%$ CI $1.06,1.47)$. These values reflect those derived from the log regression with total $\mathrm{MD}$ as the predictor; in each subsequent model with the different MD mechanisms substituted, the ORs for prior victimisation, peer support and school connectedness were substantively identical as with this
Table 1 Descriptive statistics and univariate tests of predictor variables by bystander group

\begin{tabular}{|c|c|c|c|c|}
\hline & $\begin{array}{l}\text { Proactive bystander } \\
(n=786)\end{array}$ & $\begin{array}{l}\text { Passive bystander } \\
(n=445)\end{array}$ & & \\
\hline & $\%(\mathrm{n})$ & $\%(\mathrm{n})$ & Chi-square & $p$ value \\
\hline Gender $(n=1231)$ & & & 0.0 & .930 \\
\hline Female & $64.0(403)$ & $36.0(227)$ & & \\
\hline Male & $63.7(383)$ & $36.6(218)$ & & \\
\hline Indigenous status $(n=1226)$ & & & 0.3 & .558 \\
\hline Yes & $58.6(17)$ & $41.4(12)$ & & \\
\hline No & $63.9(765)$ & $36.1(432)$ & & \\
\hline $\begin{array}{l}\text { Language other than English } \\
\qquad(n=1226)\end{array}$ & & & 0.9 & .331 \\
\hline Yes & $60.5(107)$ & $39.5(70)$ & & \\
\hline No & $64.3(674)$ & $35.7(375)$ & & \\
\hline $\begin{array}{l}\text { Parental consent procedure } \\
\quad(n=1231)\end{array}$ & & & 0.0 & .864 \\
\hline Opt-out & $64.0(639)$ & $36.0(360)$ & & \\
\hline \multirow[t]{2}{*}{ Opt-in } & $63.4(147)$ & $36.6(85)$ & & \\
\hline & Mean (SD) & Mean (SD) & $t$ & $p$ value \\
\hline Age (in years) & $13.03(0.89)$ & $13.17(0.92)$ & -2.66 & $.008 * *$ \\
\hline FBS victimisation (range $1-5$ ) & $1.64(0.70)$ & $1.49(0.64)$ & 3.76 & $<.001$ \\
\hline $\begin{array}{l}\text { School connectedness } \\
\text { (range } 1-5)\end{array}$ & $3.84(0.89)$ & $3.71(0.83)$ & 2.50 & .013 \\
\hline Peer support (range 1-3) & $2.38(0.51)$ & $2.29(0.53)$ & 3.03 & .003 \\
\hline $\begin{array}{l}\text { Moral disengagement (full } \\
\text { scale, range 1-5) }\end{array}$ & $1.54(0.55)$ & $1.68(0.72)$ & -3.51 & $<.001$ \\
\hline Moral Justification Subscale & $1.76(0.87)$ & $1.82(0.96)$ & -1.03 & .306 \\
\hline $\begin{array}{l}\text { Euphemistic Labelling } \\
\text { subscale }\end{array}$ & $1.94(0.98)$ & $2.02(1.04)$ & -1.31 & .192 \\
\hline $\begin{array}{l}\text { Diffusion of Responsibility } \\
\text { Subscale }\end{array}$ & $1.60(0.75)$ & $1.81(0.92)$ & -4.17 & $<.001$ \\
\hline $\begin{array}{l}\text { Distort Consequences } \\
\text { Subscale }\end{array}$ & $1.47(0.60)$ & $1.64(0.78)$ & -4.01 & $<.001$ \\
\hline Victim Blame Subscale & $1.25(0.51)$ & $1.40(0.70)$ & -3.85 & $<.001$ \\
\hline
\end{tabular}


Table 2 Correlation matrix for study variables

\begin{tabular}{|c|c|c|c|c|c|c|c|c|c|c|c|c|c|}
\hline & 1 & 2 & 3 & 4 & 5 & 6 & 7 & 8 & 9 & 10 & 11 & 12 & 13 \\
\hline 1. Gender & - & & & & & & & & & & & & \\
\hline 2. Age & .005 & - & & & & & & & & & & & \\
\hline 3. ATSI & -.012 & -.047 & - & & & & & & & & & & \\
\hline 4. LOTE & $.077 * *$ & .046 & -.018 & - & & & & & & & & & \\
\hline 5. Victimisation & $-.112^{* *}$ & -.011 & -.031 & .000 & - & & & & & & & & \\
\hline 6. Peer support & -.006 & -.019 & .012 & $-.085^{* *}$ & $-.315^{* *}$ & - & & & & & & & \\
\hline $\begin{array}{l}\text { 7. School } \\
\text { connectedness }\end{array}$ & $.081 * *$ & $-.094 * *$ & -.001 & -.023 & $-.319 * *$ & $.458 * *$ & - & & & & & & \\
\hline $\begin{array}{l}\text { 8. Moral } \\
\text { justification }\end{array}$ & $.152 * *$ & $.061 *$ & .013 & .019 & $.107 * *$ & $-.063 *$ & -.038 & - & & & & & \\
\hline $\begin{array}{l}\text { 9. Euphemistic } \\
\text { labelling }\end{array}$ & $.130 * *$ & .003 & .003 & .039 & $.059 *$ & -.001 & -.006 & $.590 * *$ & - & & & & \\
\hline $\begin{array}{l}\text { 10. Diffusion of } \\
\text { responsibility }\end{array}$ & $.069 *$ & .001 & .022 & .050 & $.071 *$ & $-.073 *$ & $-.066^{*}$ & $.500^{* *}$ & $.581 * *$ & - & & & \\
\hline $\begin{array}{l}\text { 11. Distort } \\
\text { consequences }\end{array}$ & $.160 * *$ & .013 & .005 & $.061^{*}$ & .040 & -.053 & -.053 & $.625^{* *}$ & $.670^{* *}$ & $.589 * *$ & - & & \\
\hline 12. Victim blame & $.119 * *$ & -.013 & .016 & $.110 * *$ & $.116^{* *}$ & $-.114 * *$ & $-.111 * *$ & $.490 * *$ & $.456^{* *}$ & $.505^{* *}$ & $.591 * *$ & - & \\
\hline $\begin{array}{l}\text { 13. Moral } \\
\text { disengagement }\end{array}$ & $.156^{* *}$ & .014 & .011 & .054 & $.087 * *$ & -.056 & -.045 & $.789 * *$ & $.845^{* *}$ & $.764 * *$ & $.865^{* *}$ & $.668 * *$ & - \\
\hline $\begin{array}{l}\text { 14. Bystander } \\
\text { behaviour }\end{array}$ & -.003 & $-.076^{* *}$ & -.017 & -.028 & $.104 * *$ & $.088 * *$ & $.072 *$ & -.031 & -.038 & $-.127^{* *}$ & $-.124 * *$ & $-.122 * *$ & $-.109^{* *}$ \\
\hline
\end{tabular}

model, indicating they are robust significant predictors of proactive bystander response.

As expected, higher moral disengagement was associated with a reduced likelihood of a proactive bystander response $(\mathrm{OR}=0.66,95 \% \mathrm{CI} 0.54-0.81)$. With respect to the individual moral disengagement mechanisms, diffusion of responsibility was significantly associated with decreased likelihood of proactive bystander responses $(\mathrm{OR}=0.70,95 \%$ CI $0.60-0.81)$. Distortion of consequences was similarly predictive of passive bystander responses $(\mathrm{OR}=0.66,95 \%$ CI $0.55-0.80)$. Finally, victim blame also was significantly associated with less proactive bystander responses $(\mathrm{OR}=0.62,95 \%$ CI $0.50-0.78)$. Moral justification $(p=.267)$ and euphemistic labelling
( $p=.098)$ were not associated with increased likelihood of proactive bystander responses.

Gender did not moderate the association between moral disengagement and bystander group. When added to the individual models in Table 3, the interaction between gender and moral disengagement (full scale and subscale scores) was not significant (all $p>.05)$.

\section{Discussion}

This study focused on proactive and passive bystanders with students who were categorised as being supportive of the
Table 3 Separate multivariable logistic regression predicting odds of proactive bystander response to observed bullying from specific and total MD mechanisms

\begin{tabular}{llllll}
\hline & \multirow{2}{*}{ Odds ratio } & \multicolumn{2}{l}{$95 \%$ CI } & \multirow{2}{*}{ Wald chi-square } & $p$ \\
\cline { 3 - 4 } & & \multicolumn{2}{c}{ Lower } & Upper & \\
\hline Moral Disengagement Scale (full scale) & .662 & .540 & .811 & 15.84 & $<.001^{* *}$ \\
Diffusion of responsibility subscale & 0.70 & 0.60 & 0.81 & 22.15 & $<.001^{* *}$ \\
Distortion of consequences subscale & 0.66 & 0.55 & 0.80 & 19.10 & $<.001^{* *}$ \\
Victim blame subscale & 0.62 & 0.50 & 0.78 & 17.98 & $<.001^{* *}$ \\
Moral justification subscale & 0.92 & 0.80 & 1.06 & 1.23 & .267 \\
Euphemistic labelling subscale & 0.90 & 0.79 & 1.02 & 2.74 & .098 \\
\hline
\end{tabular}

$* p<0.05, * * p<0.01$. Odds of proactive bystander versus passive bystander response adjusted for other variables in all models (including Indigenous status, language other than English spoken in home, parental consent type, gender, age, victimisation, school connectedness and peer support) 
bullying and those who had never seen bullying happen excluded from the analysis. This provided opportunity to explore associations of positive defenders or 'supporters'. Some important differences between proactive and passive bystanders emerged. While gender was not associated with being a passive bystander or a proactive bystander, students in the proactive bystander group tended to be a few months younger on average than those in the peer bystander group. This finding is similar to other studies that found younger students tend to engage more as proactive bystanders than older students (e.g. Bellmore et al. 2012; Ma et al. 2019) and rates of passive bystander behaviour (or doing nothing) increase with age (Trach et al. 2010). Increasing levels of bullying victimisation, peer support and school connectedness and lower moral disengagement, in particular diffusion of responsibility, distortion of consequences of being bullied, and blaming the bullying target, were associated with higher odds of a proactive bystander response.

Prior experiences of being a victim of bullying in these high school students were associated with a greater likelihood of defending responses to witnessing bullying. This contrasts with findings from a US study where sixth-grade students who had previously been victimised were less likely to help in response to witnessing bullying (Bellmore et al. 2012), but similar to our results another US study that found high school students who were bullied frequently (defined as more than twice in the previous month) were more likely than peers to be proactive in telling an adult at school (Lindstrom Johnson et al. 2013). Although Waasdorp Tracy and Bradshaw (2018) found complex, inconsistent bystander patterns for students who reported being victimised, a direct comparison with our results is not possible as our study excluded the $5 \%$ of students with combined responses and contextual factors such as relationships with other students (victims or bullies) were not measured. Thus school-based interventions need to provide specific skills for those with previous experiences of bullying victimisation to help them to intervene as proactive bystanders. Further research to explore how proactive bystanders defend, and what 'defender' or 'supporter' actions victims find most helpful, would also inform interventions as it is possible some defenders may try to stop the bullying by retaliating against the person doing the bullying (Bussey et al. 2020).

Similar to previous findings (Ahmed 2008), higher levels of school connectedness were also associated with higher odds of a proactive bystander behaviours in the current study. This may suggest feeling part of their school increases social bonding/connectedness, and a sense of responsibility to uphold school values/justice (Ahmed 2008). O'Brennan et al.'s (2014) study found students were more comfortable intervening in bullying situations when their teachers were more connected to them as students. Higher perceived levels of support from their peers were also associated with more proactive responses in our sample, possibly due to less fear of retaliation from the perpetrator of the bullying and a greater sense of support from other bystanders. If levels of peer support are high within the student cohort and assisting peers and intervening in bullying is a perceived social norm in the group, individual students may be more likely to defend targets of bullying (Evans and Smokowski 2015; Waasdorp Tracy and Bradshaw 2018). These findings highlight the importance of whole school policy and practices to enhance peer support school connectedness.

\section{Moral Disengagement}

Similar to the Ma et al. (2019) and Killer et al. (2019) metaanalyses, the present study found overall moral disengagement to be associated with a decreased odds of a defending or proactive response to bullying. Contrary to the hypotheses, gender did not moderate the relationship between moral disengagement and defending behaviour, and thereby failed to replicate the findings of Thornberg and Jungert (2013) and Doramajian and Bukowski (2015). None of the MD mechanisms were moderated by gender, extending those earlier studies. This finding simplifies the process of prevention and intervention, suggesting that consistent messaging across genders is likely to be appropriate.

A key strength of our study was use of Thornberg and Jungert's (2014) measure of mechanisms of moral disengagement specific to bullying with diffusion of responsibility, distortion of consequences and victim blame all associated with decreased proactive bystander behaviours while moral justification and euphemistic labelling were not implicated in bystander behaviour. Beyond the ubiquitous role of diffusion of responsibility and victim blame, there may be normative developmental or cultural differences that account for the role of specific mechanisms in predicting bystander behaviour. Further research is needed to determine whether the distortion of consequences is replicated in younger samples and victim blame in older student samples, and whether this difference is attributable to the Australian versus Swedish cultural context (Thornberg and Jungert 2014) and what implications this has for school-based programs in other countries.

The findings that diffusion of responsibility, distortion of consequences and victim blame are specifically related to likelihood of passive bystander behaviour provides crucial information for school bullying prevention and intervention. These findings highlight the complexity of bystander support. This suggests that the pedagogical focus on dismantling moral disengagement about the 'character building' quality of bullying, or beliefs about victims being at fault or just needing to try harder to 'fit in' might be a common point of emphasis for bullying prevention programs, and for debriefings after bullying incidents. 
The findings that moral justification and euphemistic language were not implicated in bystander support may suggest the reprehensible behaviour is in fact recognised as inappropriate. However, our findings that diffusion of responsibility, distortion of consequences and victim blame are associated with decreased proactive bystander behaviours suggest although students may recognise the behaviour as reprehensible, the need to minimise, ignore or misconstrue the consequences ultimately justifying victim blame, may be more complex and difficult for young people to address. Schoolbased interventions must recognise the complexity of these behaviours with adolescents engaging in discussion around constructive helping behaviours.

\section{Limitations}

One of the limitations of this study is that the data were collected by self-report; hence, responses may have been influenced by social desirability, resulting in an over-reporting of 'good behaviour' and an under-reporting of 'bad behaviour'. In addition, there could have been an effect of shared method variance when students were self-reporting on all the measures (Cornell and Bandyopadhyay 2010; Volk et al. 2016). Independent observations or reports of bystander behaviour would have overcome any bias arising from the use of only self-report data and strengthened the validity of the inference that can be drawn from the study. Unfortunately, such measures were not possible within the constraints of the main study.

Another limitation of the study was the very low response rate from government schools compared to a good response rate for non-government schools as a result of the opt-in and opt-out consent processes for government and nongovernment schools respectively. While the consent process was controlled for in the analyses, the low consent rates in government schools reduce the generalisability of the findings to this educational sector. A further limitation is the crosssectional nature of these data as a longitudinal study was not possible.

The timeframe for the questions about witnessing of bullying was deliberately left open to capture any relevant incidents. However, this poses a problem to understanding the relationship of prior victimisation on bystander response. It is possible that a student may have described their bystander responses to a witnessed incident that occurred before they themselves became a target of bullying. Such subsequent experience may change how one acts when witnessing other students being bullied. Future studies need to ensure care in probing the timeline of life events that might alter how one reacts to watching others being bullied.

In the current study, personal factors influencing bystanders' behaviour were studied independently of the specific relationships of the witnessed bullying participants. It is important for future research to consider the potential dependence of these factors on context. That is, explanations of bystander behaviour also depend on who was involved and the relationships between the students at the time of the incident, with students assisting friends who are victimised more than other peers (Bellmore et al. 2012). Future research therefore needs to examine both personal characteristics and situational variables, perhaps in more qualitative ways. In addition, the barriers and enablers to being a proactive bystander need further exploration.

\section{Implications}

Findings from this study reinforce the need for comprehensive, integrated school-based bullying prevention interventions. Whole school strategies to enhance school connectedness along with strategies to foster peer support are critical. The implications of classroom collective moral disengagement have been explored previously (Gini et al. 2015), highlighting the need for whole school strategies. Our study found passive bystanders were more likely to morally disengage, especially for the constructs of diffusion of responsibility, distortion of consequences and victim blame. This may be associated with the need to disassociate with the situation (Bandura et al. 1996). Programs that aim to unpack these constructs of moral disengagement with a specific focus on enhancing student skills and fostering empathy and personal responsibility are important. For example, the association between empathetic behaviour and defending is recognised in a number of studies (for example, Lambe and Craig 2020; Barchia and Bussey 2011). In China, empathetic concern was found to be a predictor of defender behaviours (Xie and Ngai 2020). Encouragingly, the subsample of proactive and passive bystanders in our study represented almost two thirds of the total sample of the broader study suggesting whole school interventions focusing on enhancing positive bystander behaviours are likely to be amenable. Further, our findings did not highlight gender differences and suggested younger students were more likely to participate in defending behaviours supporting universal programs in the early secondary school years.

This study was conducted in Australian schools and while the international literature confers with many of the findings, it is acknowledged there may be significant cultural differences that may impact the implementation of school-based interventions. For example, Yun (2019) poses the need to consider the dynamics of ethnic diversity in bullying contexts.

\section{Conclusion}

While witnessing acts of bullying does not affect all bystanders in the same way, the findings of the current study 
contribute important knowledge about differences between proactive bystanders and passive bystanders. Gender was not associated with being a passive bystander or a proactive bystander; however, younger students tended to engage in more defending behaviour. Being victimised themselves previously, being connected to school, having peer support and having lower moral disengagement were all associated with higher odds of proactive bystander behaviours.

Obtaining a better understanding of the mechanisms involved in different bystander behaviour has implications for the development of more effective anti-bullying interventions, as proactive bystander responses may be an important mechanism in decreasing bullying, with potentially more benefits than teacher intervention (Denny et al. 2015).

Acknowledgements This study was conducted as part of the Beyond Bullying: Positive Change for All study, which was funded in whole by the Australian National Health and Medical Research Council (NHMRC Project 1046086). Professor Donna Cross' contribution to this paper was supported by an NHMRC Research Fellowship GNT 1119339. We thank the schools, principals, teachers, parents and students who contributed to this research.

\section{Compliance with Ethical Standards}

Prior to recruitment, approval was obtained from the Human Research Ethics Office of the University and the offices of the State Department of Education (government schools) and Catholic Education (non-government schools). Government schools required active parental (opt-in) consent; non-government schools permitted opt-out consent for student survey completion.

Conflict of Interest The authors declare that they have no conflicts of interest.

\section{References}

Ahmed, E. (2008). 'Stop it, that's enough': bystander intervention and its relationship to school connectedness and shame management. Vulnerable Children and Youth Studies, 3(3), 203-213. https://doi. org/10.1080/17450120802002548.

Baldry, A. C. (2005). Bystander behaviour among Italian students. Pastoral Care in Education, 23(2), 30-35. https://doi.org/10.1111/ j.0264-39442005.00329.x.

Bandura, A. (2002). Selective moral disengagement in the exercise of moral agency. Journal of Moral Education, 31(2), 101-119. https://doi.org/10.1080/0305724022014322.

Bandura, A., Barbaranelli, C., Caprara, G. V., \& Pastorelli, C. (1996). Mechanisms of moral disengagement in the exercise of moral agency. Journal of Personality and Social Psychology, 71(2), 364-374.

Barchia, K., \& Bussey, K. (2011). Predictors of student defenders of peer aggression victims: empathy and social cognitive factors. International Journal of Behavioral Development, 35(4), 289-297. https://doi.org/10.1177/0165025410396746.

Barhight, L. R., Hubbard, J. A., \& Hyde, C. T. (2013). Children's physiological and emotional reactions to witnessing bullying predict bystander intervention. Child Development, 84(1), 375-390. https:// doi.org/10.1111/j.1467-8624.2012.01839.x.
Batanova, M., \& Loukas, A. (2014). Unique and interactive effects of empathy, family, and school factors on early adolescents' aggression. Journal of Youth and Adolescence, 43(11), 1890-1902. https:// doi.org/10.1007/s10964-013-0051-1.

Bellmore, A., Ma, T. L., You, J. I., \& Hughes, M. (2012). A two-method investigation of early adolescents' responses upon witnessing peer victimization in school. Journal of Adolescence, 35(5), 1265-1276. https://doi.org/10.1016/j.adolescence.2012.04.012.

Bussey, K., Fitzpatrick, S., \& Raman, A. (2015). The role of moral disengagement and self-efficacy in cyberbullying. Journal of School Violence, 14(1), 30-46. https://doi.org/10.1080/15388220.2014. 954045.

Bussey, K., Luo, A., Fitzpatrick, S., \& Allison, K. (2020). Defending victims of cyberbullying: the role of self-efficacy and moral disengagement. Journal of School Psychology, 78, 1),1-1)12. https://doi. org/10.1016/j.jsp.2019.11.006.

Campbell, M. A. (2017). Cyberbullying. In T. K. Shackelford \& V. A. Weekes-Shackelford (Eds.), Encyclopedia of evolutionary psychological science (pp. 1-7). Springer International Publishing. https:// doi.org/10.1007/978-3-319-16999-6.2495.1.

Chapin, J., \& Brayack, M. (2016). What makes a bystander stand by? Adolescents and bullying. Journal of School Violence, 15(4), 424 437. https://doi.org/10.1080/15388220.2015.1079783.

Coie, J. D., Watt, N. F., West, S. G., Hawkins, J. D., Asarnow, J. R., Markman, H. J., \& Long, B. (1993). The science of prevention: a conceptual framework and some directions for a national research program. American Psychologist, 48(10), 1013-1022. https://doi. org/10.1037/0003-066X.48.10.1013.

Cornell, D. G., \& Bandyopadhyay, S. (2010). The assessment of bullying. In S. R. Jimerson, S. M. Swearer, \& D. L. Espelage (Eds.), Handbook of bullying in schools: An international perspective (pp. 265-276). New York: Routledge.

Denny, S., Peterson, E., Stuart, J., Utter, J., Bullen, P., Fleming, T., Ameratunga, S., Clark, T., \& Milfont, T. (2015). Bystander intervention, bullying, and victimization: a multilevel analysis of New Zealand high schools. Journal of School Violence, 14(3), 245-272. https://doi.org/10.1080/15388220.2014.910470.

Dishion, T. J., Ha, T., \& Veronneau, M. H. (2012). An ecological analysis of the effects of deviant peer clustering on sexual promiscuity, problem behavior, and childbearing from early adolescence to adulthood: an enhancement of the life history framework. Developmental Psychology, 48(3), 703-717. https://doi.org/10.1037/a0027304.

Doramajian, C., \& Bukowski, W. M. (2015). A longitudinal study of the associations between moral disengagement and active defending versus passive bystanding during bullying situations. MerrillPalmer Quarterly, 61(1), 144-172. https://doi.org/10.13110/ merrpalmquar1982.61.1.0144.

Espelage, D., \& Swearer, S. (2004). Bullying in American schools: a social-ecological perspective on prevention and intervention. Lawrence Erlbaum.

Evans, C., \& Smokowski, P. (2015). Prosocial bystander behavior in bullying dynamics: assessing the impact of social capital. Journal of Youth and Adolescence, 44(12), 2289-2307. https://doi.org/10. 1007/s10964-015-0338-5.

Furlong, M. J., O'Brennan, L. M., \& You, S. (2011). Psychometric properties of the Add Health School Connectedness Scale for 18 sociocultural groups. Psychology in the Schools, 48(10), 986-997. https:// doi.org/10.1002/pits.20609.

Han, Y., Kim, H., \& Ma, J. (2015). School bonds and the onset of substance use among Korean youth: an examination of social control theory. International Journal of Environmental Research Public Health, 12(3), 2923-2940. https://doi.org/10.3390/ ijerph120302923.

Huitsing, G., Snijders, T. A. B., Van Duijn, M. A. J., \& Veenstra, R. (2014). Victims, bullies, and their defenders: a longitudinal study of the coevolution of positive and negative networks. Development and 
Psychopathology, 26(3), 645-659. https://doi.org/10.1017/ S0954579414000297.

Killer, B., Bussey, K., Hawes, D. J., \& Hunt, C. (2019). A meta-analysis of the relationship between moral disengagement and bullying roles in youth. Aggressive Behavior, 45(4), 450-462. https://doi.org/10. 1002/ab.21833.

Kline, R. B. (2005). Principles and practice of structural equation modeling.

Ladd, G., Kochenderfer, B., \& Coleman, C. (1996). Friendship quality as a predictor of young children's early school adjustment. Child Development, 67(3), 1103-1118. https://doi.org/10.2307/1131882.

Lambe, L. J., \& Craig, W. M. (2020). Peer defending as a multidimensional behavior: development and validation of the Defending Behaviors Scale. Journal of School Psychology, 78(1), 38-53. https://doi.org/10.1016/j.jsp.2019.12.001.

Lindstrom Johnson, S., Waasdorp, T. E., Debnam, K., \& Bradshaw, C. P. (2013). The role of bystander perceptions and school climate in influencing victims' responses to bullying: to retaliate or seek support? Journal of Criminology, 2013 (Article ID 780460). https://doi. org/10.1155/2013/780460

Ma, T., Meter, D. J., Chen, W., \& Lee, Y. (2019). Defending behavior of peer victimization in school and cyber context during childhood and adolescence: a meta-analytic review of individual and peerrelational characteristics. Psychological Bulletin, 145(9), 891-928. https://doi.org/10.1037/bul0000205.

Menolascino, N., \& Jenkins, L. N. (2018). Predicting bystander intervention among middle school students. School Psychology Quarterly, 33, 305-313. https://doi.org/10.1037/spq0000262.

Meter, D. J., \& Card, N. A. (2015). Defenders of victims of peer aggression: interdependence theory and an exploration of individual, interpersonal, and contextual effects on the defender participant role. Developmental Review, 38, 222-240. https://doi.org/10.1016/j.dr. 2015.08.001.

O’Brennan, L. M., Waasdorp, T. E., \& Bradshaw, C. R. (2014). Strengthening bullying prevention through school staff connectedness. Journal of Education Psychology, 106, 870-880. https://doi. org/10.1037/a0035957.

Padgett, S., \& Notar, C. E. (2013). Antibullying programs for middle/ high schools. National Social Science Journal, 40, 88-93.

Pate, C. M., Maras, M. A., Whitney, S. D., \& Bradshaw, D. P. (2017). Exploring psychosocial mechanisms and interactions: links between adolescent emotional distress, school connectedness, and educational achievement. School Mental Health, 9(1), 28-43. https://doi.org/ 10.1007/s12310-016-9202-3.

Rigby, K., \& Johnson, K. (2016). The prevalence and effectiveness of anti-bullying strategies employed in Australian Schools. University of South Australia.

Rolf, J., Masten, A. S., Cicchetti, D., Neuchterlein, K. H., \& Weintraub, S. (Eds.) (1990). Risk and protective factors in the development of psychopathology. Cambridge University Press.

Salmivalli, C. (2010). Bullying and the peer group: a review. Aggression and Violent Behavior, 15(2), 112-120. https://doi.org/10.1016/j. avb.2009.08.007.

Salmivalli, C., Lagerspetz, K., Bjorkqvist, K., Osterman, K., \& Kaukiainen, A. (1996). Bullying as a group process: participant roles and their relations to social status within the group.
Aggressive Behavior, 22(1), 1-15. https://doi.org/10.1002/(sici) 1098-2337(1996)22:1<1::aid-ab1>3.0.co;2-t.

Sandstrom, M., Makover, H. B., \& Bartini, M. (2012). Social context of bullying: do misperceptions of group norms influence children's responses to witnessed episodes? Social Influence, 8(2-3), 196213. https://doi.org/10.1080/15534510.2011.651302.

Shaw, T., Dooley, J. J., Cross, D., Zubrick, S. R., \& Waters, S. (2013). The Forms of Bullying Scale (FBS): validity and reliability estimates for a measure of bullying victimization and perpetration in adolescence. Psychological Assessment, 25(4), 1045-1057. https:// doi.org/10.1037/a0032955.

Thornberg, R., \& Jungert, T. (2013). Bystander behaviour in bullying situations: basic moral sensitivity, moral disengagement and defender self-efficacy. Journal of Adolescence, 36(2), 475-483. https://doi. org/10.1002/ab.21509.

Thornberg, R., \& Jungert, T. (2014). School bullying and the mechanisms of moral disengagement. Aggressive Behavior, 40(2), 99-108. https://doi.org/10.1002/ab.21509.

Trach, J., Hymel, S., Waterhouse, T., \& Neale, K. (2010). Bystander responses to school Bullying: a cross-sectional investigation of grade and sex differences. Canadian Journal of School Psychology, 25(1), 114-130. https://doi.org/10.1177/ 0829573509357553.

Ttofi, M. M., \& Farrington, D. P. (2011). Effectiveness of school-based programs to reduce bullying: a systematic and analytic review. Journal of Experimental Criminology, 7(1), 27-56. https://doi.org/ 10.1007/s11292-010-9109-1.

Volk, A. A., Dane, A. V., Marini, Z. A., \& Vaillancourt, T. (2016). Adolescent bullying, dating, and mating: testing an evolutionary hypothesis. Evolutionary Psychology, 13(4), 1-11. https://doi.org/ 10.1177/1474704915613909.

Waasdorp Tracy, E., \& Bradshaw, C. P. (2018). Examining variation in adolescent bystanders' responses to bullying. School Psychology Review, 47(1), 18-33. https://doi.org/10.17105/SPR-2017-0081. V47-1.

Weatherson, K. A., O’Neill, M., Lau, E. Y., Qian, W., Leatherdale, S. T., \& Faulkner, G. (2018). The protective effects of school connectedness on substance use and physical activity. Journal of Adolescent Health, 63(6), 724-731. https://doi.org/10.1016/j.jadohealth.2018. 07.002 .

Wilson, M. N., Asbridge, M., \& Langille, D. B. (2018). School connectedness and protection from symptoms of depression in sexual minority adolescents attending school in Atlantic Canada. Journal of School Health, 88(3), 182-189. https://doi.org/10.1111/josh.12595.

Xie, H., \& Ngai, S. S. (2020). Participant roles of peer bystanders in school bullying situations: evidence from Wuhan, China. Children and Youth Services Review, 110(1), 1-10. https://doi.org/10.1016/j. childyouth.2020.104762.

Yeager, D. S., Fong, C. J., Lee, H. Y., \& Espelage, D. L. (2015). Declines in efficacy of anti-bullying programs among older adolescents: theory and a three-level meta-analysis. Journal of Applied Developmental Psychology, 37(March-April), 36-51. https://doi. org/10.1016/j.appdev.2014.11.005

Yun, H-Y (2019). New approaches to defender and outsider roles in school bullying. Child Development, 00(0), 1-19. https://doi.org/ 10.1111/cdev.13312 